\title{
ACASO (E DESCASO) NAS CIÊNCIAS DA TERRA: DA TELEOLOGIA À PREVISÃO*
}

Silvia Figueirôa

\begin{abstract}
Resumo
Ao longo da história, a Terra foi concebida e explicada de diferentes maneiras, conforme os tempos, lugares e culturas que com ela interagiram e ainda interagem. Visões religiosas, filosóficas, mecanicistas, racionalistas, românticas, etc., entrelaçadas em maior ou menor grau, procuraram compreender seu funcionamento. Uma questão será destacada aqui, dado o tema do livro: Há lugar para o acaso nos processos que se desenrolam no planeta? Nossa discussão seguirá a via histórica, mais precisamente da História das Ciências, recorrendo, quando necessário, à Filosofia. Pretendemos mostrar a passagem de concepções que privilegiavam o acaso na explicação dos fenômenos - como formação e descoberta de jazidas minerais, erupções vulcânicas, terremotos, deslizamentos, inundações - para a racionalização das explicações, que se fez acompanhar de um sem número de medições, quantificações, teorias e, em decorrência, de aparatos de medida, no intuito de prever e antecipar a ocorrência mesma do fenômeno, com margens de erro cada vez menores. O debate, apesar de ancorado na perspectiva histórica, é absolutamente atual, dada a convivência cotidiana entre as perspectivas casuístas e racionalistas, que muitas vezes opõem leigos e especialistas, e que servem, quando convém, de explicação para escamotear irresponsabilidades. Ou seja: frequentemente, o acaso é usado como desculpa para o descaso. Que nos digam os desastres de Mariana e Brumadinho, por exemplo. Uma "historiografia terapêutica do acaso", portanto, faz-se necessária e urgente para que possamos lidar, crítica e conscientemente, com a dinâmica ambiental planetária.
\end{abstract}

\section{Introdução}

Porque o que está para nos acontecer, devemos aguentar nobremente, sem engenhos: pois não bá escapatória. (Esopo, "O filho e o leão pintado").

Quis o Acaso que os textos que compõem este livro fossem preparados sob a marca de uma pandemia como há um século não se via. "O acaso é o grande senhor de todas as coisas", já disse Luis Buñuel em suas memórias (1982, p. 241). O espírito deste tempo, que nos envolve de forma inescapável, fez aflorar as mais diversas manifestações sobre o imponderável. Das colunas de opinião às cartas de leitores, passando por artigos de economistas, os jornais têm sido pródigos em nos oferecê-las. Cito algumas, extraídas de uma única fonte (Jornal O Estado de S. Paulo), apenas a título de exemplo e como mote para reflexão:

\footnotetext{
${ }^{*}$ DOI - 10.29388/978-65-86678-51-2-0-f405-416
} 
"Mas tem algo que nenhum ser humano é capaz. de fazer. Prever o imponderável. E quando ele acontece, o que fazer? [...] Aprendi que o imponderável é uma constante." (PANDIANI, 2020, p. C2)

"O mais interessante é que ninguém pode controlar se será ou não infectado, mas todo mundo pode controlar, ao menos um pouco, se será ou não um vetor de contágio. (...) V amos dizer "não" ao desastre. V amos dizer "sim" ao pensamento." (BUCCI, 2020, p. A2)

"O mundo é aleatório, e por mais que queiramos nos precaver contra todos os sinistros, sempre haverá um cisne negro que embaralhará todas as cartas e mudará o nosso destino." (LEME, 2020, p. B5)

“A vida é assim. Temos planos, mas no fim não bá controle de nada?' (Leitora A.M.C, 2020, p.A2)

Concordantes na avaliação geral, há, no entanto, sutis diferenças entre as frases acima, que oscilam entre a ausência total de controle sobre o destino até a viabilidade de se exercer algum. No caso, o controle apontado como possível apoia-se na informação científica (médica). Mas quando foi que a ciência entrou na equação do acaso? Muitas vezes, sabemos que o que se deu foi o inverso. Como bem disse Ludwik Fleck (1935, apud OLIVEIRA, 2012, p. 135) a propósito das mudanças na ciência, "[...] nunca se pode prever qual direção a tropa principal escolherá, das muitas direções sugeridas pelas vanguardas. [...] Trilhas são transformadas em estradas, o terreno é nivelado, etc. [...] de modo que a paisagem passa por uma mudança significativa até se tornar o local da tropa principal."

Para pensar sobre as relações entre acaso e ciência, o presente texto traz reflexões a partir do olhar histórico sobre as Ciências da Terra, com ênfase na Geologia. Mais precisamente, recorremos à História das Ciências e, quando necessário, à Filosofia, a fim de entender o movimento que permitiu a passagem da imprevisibilidade à predição de eventos naturais, dentro de certos limites. Uma indagação é central aqui: Há lugar para o acaso na explicação dos processos que se desenrolam em nosso planeta? Pretendemos mostrar a passagem de concepções que privilegiavam o acaso na explicação dos fenômenos - como formação e descoberta de jazidas minerais, vulcanismo, terremotos, deslizamentos, inundações -, para a racionalização das explicações, que se fez acompanhar de um sem número de medições, quantificações, teorias e, como resultado, de aparatos de medida, no intuito de antecipar a ocorrência mesma do fenômeno, com margens de erro cada vez menores.

Percorrer a história dos conhecimentos ocidentais sobre a Terra permite trazer à tona duas grandes tensões epistemológicas em torno das quais os saberes se organizaram: 'acaso X destino' e 'acaso X leis naturais'. A primeira tensão, com suas marcas teleológicas e religiosas, praticamente não abre espaço para o acaso, já que tudo estaria determinado pelas leis inexoráveis da Providência (lembremos da epígrafe de Esopo) ou de uma vontade superior. Essa perspectiva implica uma teleologia, ou seja: a ideia de que metas ou fins últimos guiam a natureza e a humanidade, sendo a finalidade o princípio explicativo basilar da organização e das transformações da realidade. Infelizmente, é uma perspectiva ainda muito presente, contribuindo para aumentar nossas tragédias e passaremos de leve por ela 
neste texto, ao descrevermos a passagem da "casualidade" para "causalidade" em Geologia. No caso da segunda, igualmente reduz-se o espaço do acaso, na medida em que, ao se conhecerem as leis que governam a natureza, é factível fazer previsões e minimizar - ou suprimir - o acaso. Chamei, entretanto, de 'tensões' porque não houve e não há um absoluto nessas dicotomias: de um lado, o desconhecido que irrompe é sempre atribuído ao acaso e, de outro, sabe-se que é impossível tudo prever, até porque os seres humanos são, eles também, imprevisíveis.

Nas páginas que seguem, a problemática acima será abordada, de início, a partir da perspectiva histórica sobre as dinâmicas da natureza e da presença do acaso como componente essencial das explicações e, posteriormente, o ponto de inflexão, quando a predominância absoluta do acaso dá lugar às ideias de "leis naturais" quando do advento da "ciência moderna". Na sequência, a discussão prossegue a partir da ideia de 'objetividade científica', que é aqui entendida como construída historicamente. Ao final, as reflexões procuram se aproximar do tempo presente, deslocando o papel do acaso nos chamados "desastres naturais".

\section{A Terra, o acaso e as leis naturais ${ }^{1}$}

Ao longo da história, a Terra foi concebida e explicada de diferentes maneiras, conforme os tempos, lugares e culturas que com ela interagiram e ainda interagem. Visões religiosas, filosóficas, mecanicistas, racionalistas, românticas, etc., entrelaçadas em maior ou menor grau, procuraram compreender seu funcionamento. Algumas questões permaneceram: o planeta evolui por ciclos ou de modo unidirecional? Há marcas dos processos passados em nosso presente? Estas marcas nos ajudam na compreensão do todo? A dinâmica planetária é regular e previsível? As mudanças são lentas e graduais, ou bruscas e catastróficas? Há sentido e direcionalidade nelas?

De modo geral, até o Renascimento (séculos XV-XVI) diversas "escolas de pensamento", sobretudo europeias, mas não somente, partilhavam de uma visão integrada e unificada do Cosmos. A cristandade e a Igreja católica foram herdeiras de boa parte do conhecimento clássico (greco-romano), adaptando-o e reinterpretando-o conforme suas concepções e necessidades. Pensava-se que a Terra só poderia ser plenamente compreendida, em termos de seu lugar e função no conjunto dos corpos que integravam o universo, se estivesse situada na posição central. No mundo geocêntrico, a Terra sofreria a influência dos demais planetas e estrelas, assim como tudo o que nela se encontrava, fosse humano, animal, vegetal ou mineral. Os minerais metálicos teriam sua origem e crescimento por influência dos planetas: o ferro por ação de Marte, o chumbo, de Saturno, o ouro dependia do Sol. As gemas refletiriam a luz cósmica. A Terra era vista não somente como um planeta, mas igualmente como um elemento que perpassava toda a matéria nas regiões corruptíveis do Cosmos. Por sua vez, o planeta não seria composto somente pelo seu próprio elemento, mas também por fogo, água e ar, como proposto, dentre outros, por Aristóteles.

A coerência da visão que enxergava a Terra como parte intrínseca do universo manifestava-se também em relação à humanidade: o destino do planeta era inseparável

\footnotetext{
${ }^{1}$ A base deste item ancora-se em: GOHAU, 1992; GOULD, 1992; OLDROYD, 1996.
} 
daquele do Cosmos e, do mesmo modo, o dos seres humanos era inseparável daquele do planeta. As imponderáveis catástrofes naturais, como cometas, tempestades e terremotos, constituíam presságios de catástrofes humanas. Em praticamente todas as culturas - não apenas no continente europeu, mas também no Havaí, na Mesoamérica ou na Austrália , os vulcões, terremotos, tempestades, secas e enchentes foram considerados, eles próprios, divindades, ou ações empreendidas pelas divindades.

Mas o Renascimento europeu, impulsionado não só pela redescoberta de clássicos, mas sobretudo pelo impacto das grandes navegações e do encontro com mundos desconhecidos (com destaque para as Américas), permitiu que as concepções sobre o funcionamento do planeta experimentassem mudanças radicais. Ao possibilitarem que se testemunhasse com os próprios olhos, as viagens contribuíram para derrubar mitos estabelecidos há séculos, como o de que as águas dos oceanos ferviam nos trópicos, por exemplo. Nas palavras de Paolo Rossi (1992, p. 53):

O maior obstáculo com que se defrontam os defensores da ortodoxia bíblica é a descoberta da América [...] De fato, o continente americano não é contíguo a nenhuma parte da Ásia, da Europa, da África, e é povoado por homens e por toda espécie de animais. No aspecto, na linguagem, nos costumes, esses homens são diferentes dos asiáticos, dos europeus e dos africanos. Os animais são diferentes dos que povoam os outros três continentes. Essas dificuldades deram novo vigor às teses sacrílegas que advogavam a eternidade do mundo e a ideia de a vida originar-se da matéria. [...] Deduziu-se que ou o Dilúvio Bíblico não foi universal ou depois dele se verificou na América uma nova criação de animais.

De forma sintética, pode-se dizer que a Astronomia, redefinida por Copérnico no bojo das mudanças geradoras da modernidade, negou à Terra seu lugar central no sistema planetário, onde foi substituída pelo Sol. Ao mesmo tempo, o uso do telescópio mostrou que o mundo era quase infinitamente grande, e que a Terra e o Sistema Solar não ocupavam um sítio especial. A dicotomia da interdependência entre o macro e o microcosmo foi abandonada, bem como a redução da matéria aos quatro elementos, que perdurava há muitos séculos. Passaram a ser possíveis observações mais detalhadas dos processos superficiais, que se manifestaram inclusive na pintura (vejam-se as camadas de rochas sedimentares retratadas por Da Vinci no quadro "Madona de Yarnwinder", pintado em 1501).

Todavia, a explicação mais generalizada sobre a formação e composição da superfície terrestre permanecia imbricada ao relato cristão, isto é, ao dilúvio bíblico. Essa explicação, fundamentada pelas Escrituras, seria comprovada empiricamente pelo fato de se encontrarem fósseis de origem marinha em montanhas. Somente com o desenvolvimento de novas teorias sobre os fósseis nos séculos XVII e XVIII, aceitandoos como restos de antigos seres viventes, foi possível a ruptura com esta interpretação cristã. Ao mesmo tempo, admitir os fósseis como testemunhos do passado, permitiu que se admitisse que a Terra possuía uma história, que o planeta se transformava no tempo. E, a partir daí, que se interrogasse: como se dão estas transformações? De forma constante e cíclica, ou de maneira abrupta e linear? De modo previsível ou ao acaso?

Intensos debates se travaram para explicar as mudanças, ou passagens, de uma época a outra na história do planeta. No fundo, o que se discutia eram aspectos do método 
científico em Geologia e questões teóricas da natureza do conhecimento dessa ciência, que se conectavam por meio do problema da construção de uma interpretação teórica sobre a Terra. Como reconstituir uma história sem testemunhas, nem tampouco com um relato mais geral (como o bíblico) que lhe conferisse consistência a priorr? Os espécimes, redefinidos como 'relíquias' e 'monumentos' e não mais como objetos singulares, estavam na base do novo modo de interpretar: constituíam evidências, testemunhos, a partir dos quais interpretações, deduções e reconstruções poderiam ser feitas. A ciência geológica, assim, seria o estudo de processos e dos objetos/espécimes nesses processos, não mais tomados isoladamente.

De um lado, encontravam-se as concepções de um tempo linear. Uma obra marcante neste sentido foi Les Époques de la Nature (As Épocas da Natureza), de autoria do naturalista francês Georges Leclerc, conde de Buffon (1707-1788), que postulava que o globo, inicialmente fundido, havia se resfriado até atingir o estado atual. A história que propunha dividia-se em seis “épocas' e citava, por exemplo, vulcões extintos e fósseis como "arquivos" ou "monumentos" da natureza, pois poderiam ser considerados relíquias de um estado de coisas anterior. Os objetivos de Buffon para a História Natural iam muito além do inventário e descrição dos objetos nos "gabinetes de curiosidades", ou mesmo no mundo em geral. Esse autor pretendia trazer uma compreensão de como tudo funciona e de como se encaixam em padrões mais amplos de interdependência. Em ambas versões de sua "Teoria da Terra", inserida no volume de abertura de sua "Histoire Naturelle", fica claro que Buffon buscava formulações em termos de regras ou leis gerais (TAYLOR, 2016).

Por conseguinte, as feições naturais foram usadas cada vez com mais frequência na reconstrução de uma História da Terra que, por ser intrinsecamente contingente, não poderia ser predita a priori por nenhuma teoria mais geral. Chamava particularmente a atenção destes naturalistas a variedade de formas extintas, que iam desde enormes ossos de vertebrados semelhantes a elefantes (mastodontes) até grandes conchas com estrutura espiralada, como amonitas (conhecidos como 'Cornos de Amon', por se assemelharem aos chifres de carneiro portados pelo deus egípcio Amon).

Uma explicação inovadora, sem invocar a intervenção divina, foi desenvolvida sobretudo por outro naturalista francês, Georges Cuvier (1769-1832). Valendo-se das ricas coleções de ossos fósseis do Museu de História Natural de Paris, onde trabalhava, ele aplicou um dos princípios da Anatomia Comparada, qual seja, o da correlação entre função e estrutura, para reconstruir vertebrados extintos. Além disso, Cuvier interessava-se pela integração entre Zoologia e Geologia, por meio da reconstrução integral do ambiente físico de cada época em que viveram estas criaturas extintas, entendidas como estágios particulares do desenvolvimento da vida na Terra. A cada um corresponderiam condições climáticas e terrestres específicas, uma fauna e uma flora. Iniciava-se, assim, o que hoje é corrente na Paleontologia: a reconstrução de ambientes antigos, ou reconstrução paleoambiental. No trabalho de Cuvier e daqueles que seguiram seus passos, populações inteiras de animais extintos foram reconstruídas. Esse registro paleontológico, montado peça por peça, permitia subir na escala do tempo e das camadas até os períodos geológicos mais próximos, sugerindo que tais populações existiram numa sucessão temporal: desde um período sem evidências de vida (Azóico), seguido pelo dos invertebrados, e então pelo dos vertebrados; dos peixes aos répteis e mamíferos; dos simples aos complexos; dos extintos aos ainda existentes. A imagem construída a partir dos fósseis indicava uma 
progressiva sucessão de formas de vida que culminavam no homem, cada população aparentemente separada da outra por períodos de "revolução" - isto é, de mudanças abruptas, também chamadas "catástrofes" -, posto que o registro geológico não era linear e as interrupções em sua preservação eram frequentes.

De outro lado, temos as propostas de James Hutton (1726-1797), figura importante do Iluminismo escocês. Formado em medicina e proprietário de terras, deu especial atenção aos processos de erosão e deposição de sedimentos, pois afetavam suas terras produtivas. Para ele, o solo e as terras emersas se renovam continuamente: o material erodido se deposita no mar que, ao ser entulhado, dá lugar à terra firme, que emerge, e as regiões abatidas passam a ser ocupadas pelo mar. A erosão e as discordâncias entre camadas têm papel relevante em sua teoria. Esse processo de erosão e sedimentação repetir-se-ia indefinidamente, aí embutida uma noção de tempo cíclico, e, na sua formulação bem conhecida, poderia ser sintetizado como: "Nenhum vestígio de um início, nenbuma perspectiva de um fim". García Cruz (2013, p. 260) caracteriza as propostas de Hutton como expressões do mito do "eterno retorno", manifestando-se na "máquina sistêmica" do planeta Terra. Este funcionamento equilibrado entre destruição e reconstrução, constante e uniforme, era o que garantia a própria existência da vida. Ao longo da vida de Hutton, suas ideias teriam transitado do teórico, teleológico e deísta para uma ciência mais empírica e observacional (GARCÍA CRUZ, 2013). As obras mais tardias de Hutton - a saber, Resumo de uma dissertação concernente ao sistema da Terra, sua duração e estabilidade (1785), Investigação das leis observáveis na composição, dissolução e restauração das terras sobre o globo (1788) e os dois volumes de Teoria da Terra, com provas e ilustraçoes" (1795) -, abriram caminho para a noção de tempo longo, bem mais longo do que a cronologia bíblica levava a crer.

Ao mesmo tempo, duas formulações-chave apresentadas por Hutton (apud García Cruz, 2013, p. 265) estabeleciam que: a) "O estudo do presente permite raciocinar sobre o passado e deduzir sobre o futuro"; b) "Examinando a construção da Terra atual para compreender as operações que atuaram no passado, se poderá também extrair conclusões sobre o futuro". Estava, assim, aberta a possibilidade de previsão dos processos geológicos, por meio de um princípio metodológico que ancorava o futuro na compreensão do passado. $\mathrm{Na}$ síntese oportuna de García Cruz (2013, p. 267): "Entraba, asi, de lleno en la causalidad del mundo en todas y cada una de sus facetas, con lo que rechazaba la casualidad, y en consecuencia la idea de que los procesos naturales fuesen fruto del azar."

\section{Os 'acidentes' e a construção da objetividade científica}

Contemporaneamente às formulações huttonianas, que apenas a partir do início do século XIX começaram a ser conhecidas e aceitas na Europa continental e na América, a busca de jazidas minerais permanecia tateante, embora menos supersticiosa: "[...] ainda que sejam suspeitos e equivocados todos os caracteres por meio dos quais podemos vir no conhecimento da existência de uma mina no interior da terra, para não falar nas varinhas de aveleira com que certos impostores pretendem abusar da credulidade dos povos". (FIGUEIRÔA, 2006) Estava-se a buscar, porém, indícios promissores que pudessem confirmar - e prever - a existência de riquezas:

A presença de uma mina é anunciada pelas áreas dos rios, que ficam vizinhos a ela, nas quais se encontram palhetas do tal mineral: e também por uma terra untuosa e 
tenra. A situação do terreno costuma ser montuosa [com montes e outeiros] e muito seca principalmente nas montanhas, que formam cadeias continuadas. As fraldas das montanhas que contêm metal são comumente cobertas de árvores densas e frondosas, e os seus cumes se vestem com plantas de folhas denegridas". (FIGUEIRÔA, 2006)

Teríamos ainda que avançar bastante no século XIX para que o amplo mapeamento em escala global levado a cabo pelos Serviços Geológicos imperiais e nacionais resultasse em quantidades crescentes de dados, ensejando teorias e gerando novos modelos a subsidiar a prospecção mineral. Mas até no século XX persistiam fortes ecos do acaso na localização de bens minerais. Quando, por exemplo, a prospecção de petróleo começou a se racionalizar, Everette L. DeGolyer (1886-1956), um dos geólogos mais influentes de seu tempo, observou que era preciso sorte para encontrar petróleo. Mesmo a experiência adquirida em diferentes regiões do globo, empregando conhecimentos geológicos e tecnologia, não era ainda suficiente para dispensar o acaso (feliz) na perfuração de um local para extração de petróleo. Foram o acúmulo de dados de novas áreas de exploração e o investimento em novos métodos de pesquisa, especialmente geofísicos, aliados aos modelos que relacionavam a concentração de petróleo às estruturas geológicas, que gradualmente tornaram a previsão uma prática mais consistente. Isso ensejou a descoberta de novos depósitos, produzindo um 'círculo virtuoso' que alimenta, simultaneamente, o número crescente de campos de petróleo e modelos cada vez mais precisos (PEYERL; FIGUEIRÔA, 2020).

Os vulcões, por seu turno, malgrado o espetáculo que produziam - ou por causa disso -, foram também considerados "acidentes", eventos sui generis cuja ocorrência ligavase ao acaso das circunstâncias locais: seriam rasos, efêmeros e gerados por combustão local. Isso significava, até o século XVIII, que os vulcões não eram "essenciais", isto é, não eram parte regular do funcionamento da Terra, não integravam a "economia da natureza". Para a grande maioria dos europeus do começo da modernidade, uma erupção vulcânica era literalmente exótica (TAYLOR, 2017, p. 120). Taylor (2017) informa que tal condição "acidental" se devia a truísmos amplamente aceitos que ligavam o fogo à destruição e confusão, enquanto à água associavam-se as noções de ordem e organização. Em meados do século XIX, no âmbito da Geologia os vulcões deixaram de ser acidentes e passaram à categoria de fenômenos ordinários. Entretanto, como observa Taylor (2017, p. 125), também "[...] no discurso cientifico em geral a premissa de uma oposição entre o acidental e o geral foi dissolvida."

Penso que o deslocamento dos acidentes e do acaso que a ciência operou no cerne das explicações se deveu, em grande medida, ao processo histórico de construção do conceito de objetividade científica. De maneira instigante, Lorraine Daston e Peter Galison apresentam esse longo percurso no livro "Objectivity", que tomarei por base a seguir. Esses autores partem da pergunta-chave "como se construiu, historicamente, a categoria 'objetividade' em ciência?" e seu desdobramento: de que modo o processo de sua constituição resultou na associação, quase como um sinônimo, à noção que se tem de ciência, sobrepondo-se a outras categorias epistemológicas? A centralidade adquirida pela noção de objetividade é destacada pelos autores: “[...] a objetividade está para a Epistemologia assim como o ascetismo exacerbado está para a Moralidade. [...] A objetividade não é apenas mais uma disciplina intelectual dentre várias outras. É um sacrificio - e foi assim descrita com frequência por seus 
praticantes" (DASTON; GALISON, 2007, p. 374). Numa bela analogia, comparam a entrada da objetividade na ciência a uma avalanche: "[...] no início, algumas rochas tremendo, galhos caindo e quantidades insignificantes de escorregamento de neve; mas depois, quando as condições estão maduras, eventos isolados, ainda que pequenos, podem provocar um enorme fluxo descendente" (DASTON; GALISON, 2007, p. 49).

A tese do trabalho pode ser assim resumida: no cerne da concepção de objetividade científica estão embutidos diferentes modos de ver o mundo que são, ao mesmo tempo, sociais, epistemológicos e éticos. Aprendidos coletivamente, não devem sua existência a nenhum indivíduo ou laboratório, sequer a uma disciplina (DASTON; GALISON, 2007). Assim, 'modos de ver' tornam-se 'modos de conhecer': os hábitos de identificação de objetos e problemas e a decorrentes coleta de dados expressam "lealdades epistemológicas" - isto é, um conjunto de características intrínsecas às disciplinas - que, ao operarem na leitura do mundo natural, definem e constroem os próprios dados. Dizendo de outro modo: a produção de um dado é parte da produção de um self científico e ambos são adquiridos através da prática contínua das técnicas de representação da natureza simultaneamente à moldagem desse self.

Os autores identificam três principais padrões dos modos de ver e de representar a natureza - que, por sua vez, correspondem a diferentes tradições científicas -, a saber: 'fiel à natureza' (truth-to-nature), 'objetividade mecânica' (mechanical objectivity) e 'avaliação instruída' (trained judgment). Contrapõem historicamente as "virtudes epistêmicas" do 'fiel à natureza' e da 'objetividade mecânica', demonstrando a passagem de um ao outro - sem que nenhum deles seja eliminado por completo. No primeiro caso ('fiel à natureza'), que abrange grosso modo o século XVIII até o início do XIX, as imagens deveriam representar não o espécime individual real, mas sim o exemplar característico emblemático de toda a espécie. Isto é, o particular que representa o universal, o indivíduo que representa o conjunto. No segundo caso ('objetividade mecânica), cujo marco inicial se situa em meados do século XIX, após a invenção da fotografia, a busca consciente por modos "objetivos" de produzir imagens científicas conduz à adoção de métodos automatizados que se supunham absolutamente independentes das mãos humanas, fossem dos artistas, fossem dos cientistas. Nestes casos, a fotografia foi quase sempre preferida. A emergência da 'avaliação instruída' como modo de ver típico das ciências do século XX decorreu da insatisfação com a 'objetividade mecânica', cujas imagens passaram a ser consideradas por demais comprometidas com detalhes acidentais e com os próprios aparatos técnicos que as capturavam. A 'avaliação instruída' vai salientar, por sua vez, a concepção ascética e impessoal que se tem da ciência, com forte distinção entre o objetivo e o subjetivo nas práticas científicas. Esta virtude epistêmica, que surge para substituir a 'objetividade mecânica', vai separar o sinal do ruído a fim de interpretar os dados: identificar padrões, conjuntos de características comuns que servem de indicadores de fenômenos ou processos.

No decorrer desse longo caminho, a construção da objetividade em ciência se fez acompanhar de um sem número de medições, quantificações, teorias e, em decorrência, de aparatos de medida, no intuito de prever e antecipar a ocorrência mesma do fenômeno, com margens de erro cada vez menores. Até novas disciplinas científicas vieram à luz, como a Estatística, para dar conta da avalanche de dados. A "febre" das medições decorreu da - e acompanhou a - mutação operada pela ciência moderna em nossa forma de ler e 
explicar o mundo: a quantificação progressivamente substituiu a avaliação qualitativasensorial, conferindo primazia a grandezas mensuráveis (como tamanho, quantidade, movimento e forma) em detrimento de conceitos como odor, sabor, finalidade, mais frequentes nas interpretações dos períodos até o Renascimento. Pari passu, a instrumentação científica cresceu e se sofisticou, produzindo uma avalanche de dados que visavam, ao mesmo tempo, sustentar as teorias e convencer a audiência, fosse ela especializada ou não, ou mesmo educacional. Por exemplo, em textos para leigos as demonstrações experimentais substituíram a complexa matemática dos Principia e Optiks de Newton (LANGMAN, 2011).

Se as catástrofes anteriormente incorporadas pelos naturalistas às explicações da dinâmica da Terra somente podiam ser constatadas a posteriori, quando da leitura do registro geológico - permanecendo, portanto, no passado -, a partir do incremento e da incorporação sistemática das medições ao que se considerava 'boa ciência' elas se projetaram ao futuro, para aí deslocadas pela possibilidade de antevisão. No caso dos terremotos, toda uma rede mundial de sismógrafos foi sendo montada, e o International Seismological Summary foi estabelecido logo após a I Guerra Mundial dando continuidade a esforços anteriores do geólogo e engenheiro britânico John Milne (1950-1913). O intercâmbio de informações sobre terremotos em escala local, regional e global, aliado ao desenvolvimento de sismógrafos de precisão crescente, trouxe dados não apenas para a previsão desses eventos, mas também para a construção de um novo modelo do interior da Terra. Em paralelo, os sismógrafos aliaram-se a outros instrumentos de medida no estudo da vulcanologia, por exemplo, permitindo adequada previsibilidade das erupções e consequente evacuação das populações das áreas de riscos.

Igualmente, no campo da Meteorologia, a previsão qualificou-se enormemente, de forma quase paradoxal, já que meteora constituíam uma classe de "fenômenos que nos surpreendem”, dado seu caráter incerto e inconstante (LENOBLE, 1954; apud TAYLOR, 2017). Há até alguns anos, o descrédito do "homem do tempo" era motivo de piadas generalizadas em diversos países. Alguns historiadores, inclusive, apontam eventos meteorológicos como responsáveis por determinado curso tomado pela história. Por exemplo, perguntam-se qual teria sido o desfecho da batalha de Waterloo se não houvesse chovido de maneira anormalmente intensa na véspera do confronto, o que retardou as tropas francesas e permitiu que tropas inglesas e seus aliados germânicos se reunissem em determinada localidade, aumentando seu poder de ataque (WHEELER; DEMARÉE, 2005). Todavia, o cenário mudou, sobretudo, devido ao grande desenvolvimento da computação de grande porte (computadores potentes e rápidos) e à intensa modelagem matemática (JANKOVIC, 2004). Na atualidade, as previsões meteorológicas são levadas muito a sério e foram incorporadas às práticas da Defesa Civil, da agricultura e da aviação, dentre outras, a fim de prevenir ou minimizar desastres.

Em suma, sabemos que é impossível impedir o acaso, exercendo controle total sobre os processos naturais, em especial quando de sua interação com a esfera social. A tal ponto que contratos em diversas áreas, como a de geologia de engenharia, por exemplo, estipulam cláusulas de tratamento de 'questões adversas', em que se define que “[...] $a$ contratada é responsável pelas condições geológicas, geotécnicas e hidrogeológicas que possam ser por ela antecipadas ou previstas" (WUNDER, 2013, p. 37). Mas entre impedir o acaso e aceitar o descaso, vai uma abissal diferença, já que, como se diz popularmente: quando acontece 
uma vez, é acaso; duas, é coincidência; três, é uma regra (para o bem ou para o mal...). Dentre diversas ações possíveis, uma das principais, sem dúvida, quase um chavão, passa pela educação. Como apontam Baeta e Morais (2014, p. 337),

As periferias das grandes metrópoles brasileiras [...] são marcadas pelas moradias irregulares em locais propícios a acidentes geológicos e ambientais, e acredita-se que o uso e ocupação do solo ocorram de maneira imprópria por falta de melhores oportunidades, mas também por desconhecimento dos riscos por parte da população. Portanto, a inserção de trabalhos educacionais nessas regiões é de extrema importância para minimizar a suscetibilidade de acidentes.

No direito inalienável de todo cidadão à educação devem estar obrigatoriamente incluídas não apenas a compreensão, mas também a apropriação cognitiva sobre o funcionamento do Sistema Terra, do qual somos todos parte inextricável.

\section{Considerações finais}

O breve debate que trouxemos, apesar de ancorado na perspectiva histórica, é absolutamente atual, dada a convivência cotidiana entre as perspectivas casuístas e racionalistas, que tantas vezes opõem leigos e especialistas, e que servem, quando convém, de explicação para escamotear irresponsabilidades (LOPES; FIGUEIRÔA, 2020). Ou seja: frequentemente, o acaso é usado como desculpa para o descaso, querendo levar a crer que nada poderia ter sido previsto e evitado. Que nos digam os desastres recentes do rompimento das barragens de rejeitos da mineração em Mariana e Brumadinho, por exemplo. Ou as tragédias das enchentes constantes, como as de janeiro e fevereiro de 2020 em Minas Gerais e litoral de São Paulo. No plano mundial, a ACNUR (Agência da ONU para refugiados) estima que em 2018 houve 18,8 milhões de pessoas deslocadas por conta de desastres naturais (ou nem tanto), que, se não poderiam ser evitados, poderiam ter sido minimizados. Ainda que a ciência não seja panaceia infalível, ela é parte importante das soluções. E a educação, nos âmbitos formal e informal, é também parte imprescindível desse todo.

Retomando Buñuel, em fala lúcida e quase profética (1982, p. 356):

[...] imagino frequentemente uma catástrofe planetária que eliminaria dois bilhões de habitantes, ainda que eu me incluísse entre eles. Acrescento que essa catástrofe só teria sentido e valor, aos meus olhos, se proviesse de uma força natural, tremor de terra, calamidade inaudita, vírus devastador e invencível. Respeito e admiro as forças naturais. Mas não suporto os miseráveis fabricadores de desastres que cavam a cada dia a nossa cova comum, dizendo-nos, criminosos hipócritas: 'Impossível agir de outra maneira'.

Não, não é impossível agir de outra maneira. É inadmissível seguir agindo de modo absolutamente irresponsável. Uma "historiografia terapêutica do acaso", portanto, se faz necessária e urgente para que possamos compreender e lidar, crítica e conscientemente, com a dinâmica ambiental planetária, fazendo escolhas com alguns critérios e não deixando "ao acaso". A história nos traz lições que é mister aprender. 


\section{Referências}

A.M.C. Opinião da leitora. Tema do Dia, jornal O Estado de S. Paulo 16/04/20, p.A2.

BAETA, L. de F.; MORAIS, N. L. de. Educar para prevenir: proteção e defesa civil nas escolas. Por um currículo escolar vivo. Campinas, Terræ Didatica, v. 10, n. 3, p. 336-345, set-dez 2014.

BUCCI, E. Artigo. Espaço Aberto, jornal O Estado de S. Paulo 26/03/20, p.A2.

BUÑUEL, L. Meu último suspiro. Rio de Janeiro: Nova Fronteira, 1982.

ESOPO. Fábulas, seguidas do Romance de Esopo. Seleção, tradução e apresentação de André Malta e Adriane da Silva Duarte. São Paulo: Editora 34, 2017.

FIGUEIRÔA, S. F. de M. Metais aos pés do trono: exploração mineral e o início da investigação da Terra no Brasil. São Paulo, Revista USP, n. 71, p. 10-19, set./nov. 2006. DASTON, L.; GALISON, P. Objectivity. New York: Zone Books, 2007.

GARCÍA CRUZ, C. M. James Hutton (1726-1797) y el mito del eterno retorno: interpretación de la Tierra en el siglo XVIII. Zaragoza, Llull, v. 36, n. 78, p. 259-282, 2013.

GOHAU, G. História da Geologia. Portugal: Publicações Europa-América, 1992.

GOULD, S. J. Seta do tempo, ciclo do tempo. São Paulo: Companhia das Letras, 1992.

JANKOVIC, V. Science migrations: Mesoscale weather prediction from Belgrade to Washington, 1970-2000. Social Studies of Science, v. 34, n. 1, p. 45-75, February 2004.

LANGMAN, P. The audience is listening: reading writing about learning by doing. In: HEERING, P.; WITTJER, R. Learning by doing: experiments and instruments in the history of science teaching. Stuttgart: Franz Steiner Verlag, 2011. p. 31-54.

LEME, P. Artigo. Economia, jornal O Estado de S. Paulo 05/04/20, p.B5.

LOPES, M. Margaret; FIGUEIRÔA, S. F. de M. The history of geology meets disasters: A Brazilian perspective.Chicago, ISIS, v. 111, n. 1, p. 104-111, jan-mar 2020.

OLDROYD, D. R. Thinking about the Earth: a history of ideas in Geology. London: Athlone, 1996.

OLIVEIRA, B. J. de. Os circuitos de Fleck e a questão da poularização da ciência. In: CONDÉ, M. (Ed.). Ludwik Fleck: estilos de pensamento na ciência. Belo Horizonte: Fino Traço, 2012. p.121-143. 
PANDIANI, B. Entrevista. Direto da Fonte, jornal O Estado de S. Paulo 18/03/20, p.C2.

PEYERL, D.; FIGUEIRÔA, S. F. de M. Applied geophysics in Brazil and the development of a national oil industry (1930 - 1960). History and Technology, v. 36, n. 1, 22p., jan-mar 2020.

ROSSI, P. Os sinais do tempo: história da Terra e história das nações de Hooke a Vico. São Paulo: Companhia das Letras, 1992.

TAYLOR, K. L. Before volcanoes became ordinary. In: MAYER, Wolf; CLARY, R. M.; AZUELA, L. F.; MOTA, T. S.; WOKKOWICZ, S. (eds) History of Geoscience:

Celebrating 50 Years of INHIGEO. Geological Society, London: Special Publications, 2017. p. 117-126.

WHEELER, D.; DEMARÉE, G. The weather of the Waterloo campaign 16 to 18 June 1815: did it change the course of history? London, Weather, v. 60, n. 6, p. 159-164, June 2005.

WUNDER, E. Reflexões sobre o modelo geológico no acordo contratual. São Paulo, Fundações \& Obras Geotécnicas, n. 39, p. 36-37, dezembro 2013. 